DOI: $10.17805 / z p u .2019 .3 .4$

\title{
Осознание возможности самотворчества в Античности: школа Пифагора
}

\author{
А. А. ГОРЕЛОВ \\ ИНСТИТУТ ФИЛОСОФИИ РАН, \\ Т. А. ГОРЕЛОВА \\ МОСКОВСКИЙ ГУМАНИТАРНЫЙ УНИВЕРСИТЕТ
}

В статье анализируется смысл понятия «самотворчество» и дается разграничение между близкими понятиями «творчество», «самосовершенствование», “творчество жизни», «культура себя» и «самоактуализация». Самотворчество понимается как особая разновидность творчества, относящегося к самому творцу, который пытается изменить себя в соответствии со своими представлениями об идеале. В творчестве как природной способности человека заложен и момент самотворчества.

Первые сознательные установки самотвочества зарождаются в осевое время в философии, а систематическую методологию изменения поведения человека на ее основе находим в знаменитой в Античности школе Пифагора. Здесь была создана особая система воспитания, позволяющая выявить потенциал человека и помочь ему в достижении момента самораскрытия. Учение Пифагора закладывает общие основания концепции самотворчества.

Ключевые слова: самотворчество; творчество; самосовершенствование; творчество жизни; культура себя; самоактуализация; Античность; Пифагор

\section{ВВЕАЕНИЕ}

$\mathrm{M}$ ы понимаем самотворчество (СТ) как особую разновидность творчества, относящегося к самому творцу, который пытается изменить себя в соответствии со своими представлениями об идеале. Очевидно, следует провести разграничение между близкими понятиями «творчество», «самосовершенствование» и «самотворчество». Под творчеством в широком смысле понимается создание качественно нового. Аревнерусский корень «твор», означающий вид, наружность, создание, сочетание, восходит к индоевропейскому «vor», «ver»- «открывать». В словаре В. Ааля одно из значений творчества — «давать бытие» (Ааль, 1999: 394). Это возвращает нас к мифам о происхождении мира и к библейскому представлению, в соответствии с которым мир был «творением, т. е. абсолютной новизной» (Бердяев, 1993: 117), а Бог - Творцом. «Творчество в мире потому только и возможно, что мир сотворен, что есть Творец. И человек, сотворенный Творцом и по его образу и подобию, есть также творец и призван к творчеству» (там же). Способность человека к творчеству проявляется как отзвук «образа и подобия Богу». Платон называл творчеством ( ппоэсис») «все, что вызывает переход из небытия в бытие... и следовательно, создание любых произведений искусства и ремесла» (Платон, 1993: 115). Можно предположить, что творчество служит «высвобождению скрытого» (Г. Марсель) не только в мире, но и в самом человеке. Точно так же С. $\Lambda$. Франк видит в творчестве «...выхождение за пределы себя самого, “переливание через край”, возникновение доселе не бывшего» (Франк, 1990: 247), рождение определенности из неопределенного. Состояние личности, осуществляющей «высвобождение скрытого», «выхождение за пределы себя» несет особый потенциал, открывающий нечто, до того скрытое в самом человеке, - его духовную потенцию, «так как в самой природе... “художник” или “творец... находится сам внутри формируемого им материала» (там же: 248). Хотя Франк не использует понятия СТ, его понимание творчества - «во всех областях, в которых оно может вообще 
иметь место, - означает прорыв в нашем непосредственном самобытии, в нашей субъективной жизни» (там же: 399), т. е. имеет аспект СТ.

Н. А. Бердяев относит возможность СТ к людям особого типа - святым. «Святому может быть присуща гениальность в самотворчестве, в превращении себя в совершенную просиянную тварь, хотя никаких продуктов он может и не создавать» (Бердяев, 1993: 120). Но можно понимать СТ шире, предполагая, что это общечеловеческая способность открывать «двери внутрь себя», т. е. рассматривать это как возможность самостоятельного творения души. Тогда творчество и СТ выступают как две стороны единого процесса духовной эволюции человечества, осуществляющейся только в случае их постоянного взаимовлияния. Аиалектика их отношений вскрывает и «трагический конфликт творчества и личного совершенства... великий творец может быть гулякой праздным, может быть ничтожнейшим из детей ничтожных мира» (там же). Творчество дается «ни за что», просто так, и творец оправдан своим творчеством: «Мне есть, что спеть, представ перед Всевышним, мне есть, чем оправдаться перед Ним» (В. Высоцкий).

Можно увидеть в творчестве динамический момент трансформации телесного в духовное и далее духовного в телесное (Горелов, 2013: 180): человек, будучи существом телесным, создает духовные модели - образы, символы, ценности, которые в результате последующей трансформации духовного в телесное (вхождение идеального образа в телесное) превращаются в объективные продукты деятельности человека священные книги, философские трактаты, художественные сочинения, научные открытия, картины и т. А. При СТ на первом этапе как бы возникает замысел о себе и устремление к реализации, создается некий идеальный образ, который на втором этапе входит в реальную жизнь автора, изменяя его, т. е. продуктом, произведением становится сам человек как духовно-телесное существо. Если творчество есть создание и реализация культурных смыслов, то СТ есть создание и реализация смысла жизни.

Цель работы - показать, как закладывались некоторые общие основания концепции СТ в ранней Античности на примере школы Пифагора. Несмотря на мистикомифологический габитус этого учения, оно широко использует понятие творчества (хотя и преимущественно математического) и его влияние на жизнь человека через осознание гармонии этой жизни и Космоса.

\section{СООТНОШЕНИЕ ПОНЯТИЯ СТ СО СХОАНЫМИ ПОНЯТИЯМИ}

СТ также пересекается, но не совпадает полностью с самосовершенствованием. Если взять за основу сравнения корень этих слов, то СТ направляет человека с доВерием отвориться духовному потоку, тогда как совершенствование ориентирует на движение, у которого есть вектор - вершина. Главная составляющая СТ - новизна, а самосовершенствования - нравственно-моральные установки. СТ предстает как вершина самосовершенствования, когда человек находится в пространстве полной свободы, устремляясь за границы собственной личности, конкретного социума и времени в сферу духа.

Кроме среза «телесное - духовное» в творчестве можно выделить ось «творение культуры - творение жизни». Творение культуры - общепринятое понятие, отражающее возможность создания новых образцов в различных отраслях культуры искусстве, мифологии, философии, религии, науке. Идея «жизнетворения»впервые 
была высказана теоретиком русского символизма А. Белым, который рассматривал творчество как разыгрывающуюся драму. «Первый акт творчества есть создание мира искусств; акт второй: созидание себя по образу и подобию мира; но мир созданных форм не пускает творца в им созданное царство свободы; у порога его стоит страж: наше косное "я"; борьба с собственной бренною формой, со стражем порога, и есть встреча с роком, трагедия творчества <...> Акт третий: вступление в царство свободы и новая связь безусловно свободных людей для создания общины жизни по образу и подобию новых имен, в нас таинственно вписанных духом» (Белый, 1990: 485; курсив источника. - A. Г., Т. Г.). По мнению Е. О. Тарновской, Белый настаивает: чтобы «совершить подвиг перерождения мира, человек должен переродиться сам» (Тарновская, 2003: 385). Если понимать творчество в широком смысле как творчество культуры в целом, то концепция А. Белого связывает его с творчеством жизни самого творца (т. е. с СТ), причем, как отмечает русский писатель, это внутренняя революция, которая требует героических усилий и служения высшему началу.

Сходный мотив звучит в концепции «культуры себя» или «эстетики существования» М. Фуко. Человек конца XX в., ощущающий инволюционные тенденции мира и не поддерживаемый более ни традицией, ни разумом, должен стать «художником самого себя», т. е. найти внутренний источник для обретения автономии, без которой современность больше не может обойтись (Фуко, 2007: 24). Критикуя эстетизм позиции М. Фуко, П. Адо понимает под этой внутренней работой стремление к «преобразованию», «преображению», «самопревосхождению» (Адо, 2005: 286). На наш взгляд, противоречия тут нет, так как творчество себя вкдючает все три состояния, отмеченные Адо как собственные этапы. Массовизация привела человечество к такому уровню гомогенизации, при котором творчество как необходимый механизм эволюции становится все менее возможным. Преобразование может начаться как бы с другой стороны - от человека: СТ - это шаг в сторону синергетической динамики развития.

СТ корреспондирует также к понятию «самоактуализация», возникшему в психологии XX в. Создатели теории самоактуализации А. Маслоу и К. Роджер увидели взаимообусловленность и взаимовлияние самоактуализации и творческой способности человека. А. Маслоу выделял несколько сторон самоактуализации: принятие себя, других и природы; разъединение, беспристрастность; желание уединения; автономность; сопротивление инкультурации; проблемоцентризм; демократическая структура характера (цит. по: Runco, 1999: 533). А. Маслоу, называвший самореализующихся людей «высшей ступенью человеческой зрелости», приходит к выводу, что на этой стадии «многие дихотомии, полярности и конфликты приходят к единству, преодолеваются или разрешаются». «Самореализующиеся люди одновременно эгоистичны и бескорыстны, индивидуалисты и коллективисты, рациональны и нерациональны, связаны с другими людьми и отстранены от них, поклоняются одновременно Аионису и Аполлону» (Маслоу, 1997: 125). Эти качества и противоречия можно отнести и к характеристике творческой дичности. К. Роджер пошел дальше, определив понятие «творчество» через самоактуализацию: «Творчество... человеческая способность актуализировать себя, стать более потенциальным» (цит. по: Runco, 1999: 533). Он понимал творчество как изначальную потребность человека, которая должна быть удовлетворена, а самоактуализацию как внутреннюю настроенность творить - в рамках искусства, науки и, добавим, СТ. Не известно, что первично - творчество или самоактуализация, но одно ведет к другому, и они взаимозависимы. В теории двух выдающихся психологов-гуманистов творчество понимается как потенциальная способ- 
ность любого человека, как повседневная способность создавать что-то для себя новое. Но эту способность к новизне необходимо пробуждать и чаще всего именно само-пробуждать, для чего и необходима самоактуализация. По Маслоу, можно говорить о «творчестве самоактуализации», которое, как «излучение», пронизывает всю жизнь, невзирая ни на какие проблемы (Маслоу, 1997: 184). Согласимся с авторами концепции самоактуализации, что для любого творчества, в том числе и СТ, необходимо «включение»- заинтересованность, волевое усилие, осознание цели и т. А. Но эта зависимость не абсолютна: вероятно, возможно СТ без самоактуализации и самоактуализация без СТ. Творчество и самоактуализация - многоликая конструкция, связи в которой не столь очевидны и единичны в силу уникальности каждой творческой личности.

В связи с вышесказанным можно выделить три функции СТ. Во-первых, любой вид творчества бессознательно оказывает влияние на творца, хочет он того или нет. Чтобы создать новое, надо измениться самому, стать обновленным. Вторая функция СТ заключается в сознательном воздействии творения культуры на человеческое бытие, что обнаруживается в древности в магии, а в наше время в науке (особенно в системе «наука - техника»). Хотя в этом случае речь идет не о внутреннем, а о внешнем бытии - социальном, политическом, экологическом и т. п. Третья функция представляет собой сознательное, как и в предыдущем случае, воздействие на самого себя, но как самоцель, а не как побочный продукт создания произведений культуры. В этом случае СТ становится прямой и главной целью. Такой путь характерен для мистики и религии. Святой не тот, кто хорошо говорит и пишет, а тот, кто поступает в соответствии со своими идеалами, ради утверждения которых он готов жертвовать собственной жизнью.

Пути СТ - самоактуализация, самопознание, самовыражение, выявление и развитие одаренности и способностей, самовоспитание деловых качеств - являются в то же время механизмами создания личности как единства сознания (интеллекта) и поведения (нравственности), проявляющегося в деятельности через чувства и волю. Поэтому контуры эволюционного развития СТ совпадают с контурами исторического становления индивидуальности и личности как общего потока духовной эволюции человечества. Сознание Homo sapiens проходит несколько стадий от алогичного мышления, способствующего становлению коллективного бессознательного, через родовое коллективное сознание к индивидуальному сознанию, проявившемуся в осевое время. Многомерность осевого времени отразилась в параллельно происходящих процессах диффреренциачии - сознания (утверждение рациональности), культуры (появление новой отрасли культуры), общества (разделение общественного труда, социальная дифференциация) и интеграции - проявление индивидуальности и личности как материальной (телесной), социальной (по Аюркгейму, «орган общества») и духовной Единицы. В олицетворении народившейся рациональности - философии - отражается познавательный интерес человеческой личности к миру (античная физика), к способности познавания (логика) и к самому себе (этика). Причем, если природный мир и познавательная способность разума воспринимаются как данные свыше и не поддающиеся корректировке, то возможность самоизменения, будучи также врожденной чертой человека, напротив, способствует динамике личности. Поэтому первые сознательные установки СТ зарождаются именно в философии. Этапы осознания духовной индивидуальной свободы начинаются в Античности с кодексов Семи мудрецов и философской школы Пифагора. 


\section{ЗНАЧЕНИЕ ШКОАЫ ПИФАГОРА В СОЗААНИИ}

\section{КОНЦЕПЦИИ СТ}

Первые широкие и одновременно универсальные обобщения о намерениях самоизменения были сделаны семью греческими мудрецами, жившими в период от 640 до 560 г. до н. э.: Фалесом из Милета, Питтаком из Митилены, Биантом из Приены, Солоном из Афин, Клеобулом из Аинда, Мисоном из Хены, Хилоном из Аакедемонии, которые, «собравшись вместе, посвятили Аполлону в Аельфийский храм первинки своей мудрости, начертав [на его стене] то, что все повторяют: “Знай самого себя" и “Ничего слишком"» (Платон, цит. по: Фрагменты ранних ... , 1989: 91). «Первинки мудрости», т. е. некий кодекс самоизменения у каждого из семи был свой, но первым, главным пунктом у каждого было утверждение, исходное от тех двух из Аельфийского храма, - Клеобул: «мера лучше всего»; Солон: «ничего слишком»; Хилон: «знай себя»; Фалес: «где порука, там беда»; Питтак: «знай меру» (там же: 92-93). Платон уверен, что древние мудрецы понимали, что «"знай себя" и “владей собой” - одно и то же» (там же: 92). Целью знания о внешнем мире природы и внутреннем мире души является возможность овладения самим собой.

Систематическую методологию формирования подхода на основе СТ находим в знаменитой в Античности школе Пифагора, потенциал которой позволил ей просуществовать несколько столетий. Аиоген Ааэртский называет Пифагора тем, «кто открыл таинства философии и учил им» (Аиоген, 1986: 319). Пифагор, в отличие от семи мудрецов, ощутил, что мудрость как Божественное знание недостижима, человек может лишь быть устремленным к ней как к совершенству. Такое устремление он и назвал philo-sopbia - «дружбой с мудростью» ради познания мира и себя.

Предпосылкой становления философии как отрасли культуры является рационализация мышления - введение отвлеченных сущностей, а окончательно укрепляется она тогда, когда эти сущности начинают рассматриваться как понятия, формирующиеся в мозгу человека и выступающие в качестве предмета мышления. От вечных и неизменных понятий берет начало философия, и именно они - гарант бессмертия человеческого духа. В данном пункте философия освобождается от подчинения мифу (так как имеет дело с понятиями) и религии (так как образовывает собственное объяснение бессмертия человека через вечность его духа).

В связи с тем что концепция Пифагора была одной из первых попыток философствования в Античности, она несет в себе черты переходности от предшествующих отраслей культуры - мистики и мифологии - к возникающей на их основе философии. По Аиогену, многие из своих воззрений первые греческие философы почерпнули у магов - персидских, ассирийских и египетских. Греческая культура преодолевает свое мифологическое прошлое именно «в тот момент, когда философы рационально вырабатывают представление о Боге по образу мудреца» (Адо, 2005: 244). Поэтому главная идея Пифагора, как одного из первых философов, существенно шире «варварских» мифологических концепций и в переводе на язык современных понятий сводится к тому, что можно «понять инъолюиию духа в материю путем мирового творчества и его эВолющию или восхождение к единству посредством индивидуального творчества, которое осуществляется благодаря развитию сознания» (Шюре, 1990: 219). Таким образом, кроме общепринятого как на Востоке, так и на Западе представления о том, что для приобретения «высшего знания» необходимо с помощью воли победить низшее существо в человеке, Пифагор ощутил обязательность особой сферы творчества в жизни человека для его саморазвития. Такой центральной фигурой всеобщего 
творчества он признавал священную математику как «науку чисел или всемирных принципов» (там же).

Имея в виду классификацию духовных упражнений П. Адо (Адо, 2005) - «научиться жить»; «научиться вести диалог»; «научиться чтению»; «научиться умирать», - Пифагора в большей степени следует отнести к тем, кто стремился «научиться жить». «Жизнь, говорил он, подобна игрищам: иные приходят на них, чтобы состязаться, иные - торговать, а самые счастливые - смотреть» (Аиоген, 1986: 309). Последних он называл философами, «любомудрами» и методом отбора пытался отыскать их среди окружающих. Была создана система пифагорейского воспитания, которая позволяла выявить потенциал людей третьего типа и помочь им достичь момента самораскрытия. Система первоначального тестирования была очень жесткой: стремящегося к посвящению заставляли провести ночь (12 часов) в одиночестве в пещере со страшной репутацией присутствия привидений, а затем голодного и в дурном расположении духа выставляли на всеобщее посмешище. Учитель наблюдал за реакцией человека, унижаемого необычной ситуацией незаслуженных оскорблений. Те, кто не плакал, не приходил в ярость, не проявлял ненависти, считались выдержавшими испытание в самообладании и объявлялись способными обучаться в школе.

Первый этап обучения у Пифагора Э. Шюре называет подготовлением. «Послушники или слушаюшие должны были соблюдать во время уроков абсолютное молчание» (Шюре, 1990: 247: здесь и далее курсив источника. - А. Г., Т. Г.), не имея права ни расспрашивать учителей, ни возражать, но должны были долго размышлять над содержанием уроков. Образцом для ученика была статуя Музы молчания. Пифагор «стремился прежде всего развить в своих учениках высшую способность человека: интуичию» (там же), а также привить им определенные моральные установки. Он учил, что родителей нужно уважать, какие бы они ни были (потому что они даются судьбой, т. е. высшей силой), а друзей нужно уметь выбирать (потому что «друг есть наше второе я» (там же: 248)). Утром и вечером ученики пели «золотые стихи», в которых выражались правила поведения, например «почитай память благодетельных героев» (там же: 249). По Аиогену Ааэртскому, система духовных упражнений у Пифагора трактовалась в виде «знаков». Например, «огонь ножом не разгребать» - это следовало понимать так: человека гневного и надменного резкими словами не следует задевать; «через весы не переступать» значило избегать алчности; «на хлебной мере не сидеть» означало заботиться о нынешнем и будущем в равной мере; «сердце не есть» значило не подтачивать душу заботами и страстями (Аиоген, 1986: 311). В общении он советовал держаться так, «чтобы не друзей делать врагами, а врагов друзьями. Ничто не мнить своею собственностью» (там же: 313). Подобными иносказаниями и предписаниями он и пытался настроить человека на новый образ мыслей о жизни.

Второй этап в школе Пифагора носил название очищения. На нем послушник становится полноценным учеником и постигает все тайны концепции Пифагора о числовой и всеобщей гармонии мира естественного, мира человеческого и мира божественного - материи, души и духа. Подготовкой к очищению являлось «лечение музыкой» (Фрагменты ранних ..., 1989: 493), которая делает души гармоничными, «чтобы они могли вибрировать на дуновения истины» (Шюре, 1990: 249). Это было возможно, потому что священная математика была одновременно и более трансцендентна, и более жизненна по сравнению с той математикой, как мы ее понимаем сейчас. Она «рассматривала Число не как абстрактное количество, но как существенное и деятельное ка- 
чество верховной Единищы, Бога, источника мировой гармонии» (там же: 252-253). В трансцендентной математике единица рождается от умножения нуля (обозначающего вечное Бытие) на бесконечное (обозначаемое кругом или змеей, кусающей себя за хвост, как символ движения по собственному импульсу) (там же: 255). По Пифагору, Единица, или великая Монада, «действует по принципу Аиады», в которой присутствуют «начало мужское, активное, животворящее, и начало женское, пассивное, или пластическая живая материя» (там же: 256). В их непреодолимом влечении друг к другу рождается «мечта бесконечного творчества и темное предчувствие, что Вечно-Мужественное и Вечно-Женственное достигнут совершенного слияния лишь в недрах Бога» (там же). Аиада своей творческой производительной способностью вызывает к жизни вселенную как проявленный мир, который имеет три концентрические сферы: мир естественный, мир человеческий и мир божественный (которые в человеке выражаются как тело, душа и дух). Мистика чисел, по Пифагору, далее приходит к Тетраде, которая объединяет в Монаде троичность человеческую и божественную; от числа «четыре» приходим к Семи, которое выражает гармонию семи музыкальных ладов, семи цветов, семи планет (шести планет, которые тогда были известны, плюс Солнце) и соединение человека с божеством (там же: 260); священная Аекада, образующаяся в результате сложения первых четырех чисел $(1+2+3+4)$, выражает сначала развившиеся, а затем слившиеся в новом единстве начала Божества (олицетворением Аекады являются девять Муз во главе с Вестой - хранительницей первичного Огня). Пифагорейская мистерия чисел звала не только к познанию мира, но к проникновению в глубины человеческие и возвышению на пути к божественному.

На третьем этапе достигались истинное (понимающее) знание и умение и происходило посвящение в совершенную жизнь. По Пифагору, дух, чтобы быть деятельным, не может существовать как отвлеченная сущность, но «должен иметь орган; этот орган есть живая душа» (там же: 271). Но душа двойственна: являясь пленницей тела, она «бьется между своими двумя спутниками, из которых один - змей, сжимающий ее в бесчисленных кольцах, а другой - невидимый гений, призывающий ее» (там же: 270). Ауша ощущает результаты своего «поведения», ибо «...добродетель есть лад ( barmonia), здоровье, всякое благо и бог» (Аиоген, 1986: 315). Осознание присутствия внутреннего лада и гения открывало духовное зрение, которое позволяло перейти от духовного знания к духовной жизни как результату духовной эволюции. В соответствии с его концепцией, существование души имеет две стадии, необходимые для ее развития, - земную, после рождения, и духовную, после смерти. Стадии связаны между собой: «...преступления порождают искупительную (духовную. - А. Г., Т. Г.) жизнь; несовершенная жизнь вызывает жизнь, полную испытаний. Праведная жизнь влечет за собой высокое призвание; высшая жизнь - силу творчества» (Шюре, 1990: 279). В процессе перевоплощений душа получает все больший шанс к высоким состояниям и обладанию гением. Апофеозом ее жизни является не погружение в нирвану, как считала восточная мудрость, не состояние бессознательности, но «творческая деятельность в божественном сознании... пробуждение» (там же: 282).

На четвертом этапе осуществлялось посвящение воли, идущее за посвящением разума, - «состояние совершенства, в котором посвященный, соединив свою душу с Богом, созерцает полноту истины» (там же: 283). Таким образом, человек достигает идеала через утверждение трех совершенств: «истины в разуме, праведности в душе и чистоты в теле» (там же), к которым присоединяется господство воли над всем существом человека. Отсюда и рождается общее понимание смысла жизни, выраженное 
в «золотых стихах Пифагора»: «Ты увидишь, что муки, пожирающие людей, / Суть плоды их же выбора; и что несчастные / Ищут далеко от себя тех благ, источник которых находится в них самих» (там же: 289). Ауша человека - микрокосм, в глубине которого запечатлены законы и гармония мира: «Познай самого себя, и ты познаешь Вселенную». По Пифагору, обращение внутрь себя, которое следует из этого вывода, не требует специальной аскезы, напротив, сопровождается простой методологией самоизменения, пригодной для любого и в любом месте: «Не допускай ленивого сна на усталые очи, / Прежде чем на три вопроса о деле дневном не ответишь: Ч Чо я сделал? Чего я не сделал? И что мне осталось <...> А перед тем, как встать, такие: “Аумой раскинь, какие дела тебе день приготовил” (Порфирий, 1986: 422). Полное овладение собой заканчивает работу разума, души и тела, подводит душу к гармоничному состоянию и служит проверкой действенности всей духовной работы. «Философия, которую он исповедовал, целью своей имела вызволить и освободить врожденный наш разум от его оков и цепей» (там же: 423).

Посвященные в школе Пифагора образовали общину, поскольку Пифагор первым провозгласил, что «у друзей все общее и что дружба - равенство. И ученики вносили свои состояния в одну общую кассу» (Фрагменты, 1989: 148). Социальным результатом школы Пифагора стало формирование слоя, который можно назвать духовной элитой. Совет из 300 пифагорейцев в течение нескольких десятилетий управлял государственными делами в нескольких южноиталийских полисах. Жесткая система отбора в школу привела к тому, что многие из не прошедших посвящение, затаивали зависть, злобу, ненависть и к Пифагору, и к его ученикам. По легенде, кротонец Килон, который не прошел отбор, и Пифагор отказал ему в посвящении, настолько обозлился, что начал непримиримую борьбу с ним и его общиной. «Под конец козни против них достигли таких размеров, что, когда пифагорейцы заседали в доме Милона в Кротоне и обсуждали государственные дела, [килоновцы] подпалили дом и сожгли всех пифагорейцев, кроме двоих: Архиппа и Аисида» (там же: 146). Этот первый опыт СТ показывает, что на пути самотрансформации существуют не только внутренние препятствия, но и внешние - зависть, непонимание и ненависть тех, для кого путь СТ закрыт. В любые эпохи выбравший такую дорогу не только ставит тотальный духовный эксперимент над собственной жизнью, но еще и рискует ею ради идеала.

\section{ЗАКАЮЧЕНИЕ}

Несмотря на мистико-мифологический габитус учения Пифагора, оно закладывает некоторые общие основания концепции СТ. Во-первых, СТ неразрывно связано с творчеством в широком смысле слова (хотя Пифагор имел в виду преимущественно математическое творчество): творчество стимулирует СТ, в отсутствие творчества СТ невозможно. Во-вторых, склонность к СТ определяется волей. Хотя творческий потенциал людей различен (о чем Пифагор говорил довольно жестко, утверждая, «что не из каждого дерева можно вырезать Меркурия» (Шюре, 1990: 244)), свобода воли позволяет каждому человеку осознать свои возможности, направив ее на решение избранных творческих задач. В-третьих, СТ - это фактически единственный способ духовной самоидентификации, обретения индивидуальности и своего места в мире в материальной, социальной и духовной сферах. В-четвертых, во все времена существовала зависимость между доминирующими склонностями индивидов и спецификой общества, в котором они живут. По Пифагору, эта связь имеет не только социальный, 
но и универсальный смысл - «между общественными обязанностями и гармонией Космоса», и она вызывает «предчувствие всемирного закона аналогий и соответствий» (там же: 248), т. е. имеет и духовное содержание.

Аревняя Греция стала прародительницей философии, с одной стороны, как отрасли духовной культуры, а с другой - как практического способа овладения собой телом, душой и разумом - в силу особенностей ее социальности. Аревний Египет под властью фараонов, Аревний Китай под властью императоров почти неизменно просуществовали в течение нескольких тысяч лет. В мелких полисах-государствах Аревней Греции формы правления, напротив, сменялись быстро и динамично: монархии превращались в демократии, а последние - в тирании. Из шести типов правления, обнаруженных Аристотелем в III в. до н. э., - монархии, тирании, аристократии, олигархии, демократии и политии - только последняя не была представлена в реальной политической жизни и понималась им как идеальная цель гармоничного устройства государства. Можно предположить, что внутренняя динамика личности, развитие СТ связаны с внешними социальными условиями - не столько с уровнем благополучия общества, сколько с уровнем его неустойчивости и скоростью изменений.

Пифагор стал создателем синтетической системы, примирявшей «физиков», изучавших природу и Вселенную, и «этиков-моралистов», пытавшихся изменить поведение человека. Кротонский философ, не претендовавший на творчество ни в смысле постижения природы мира, ни в том, что касается внутренней природы человека, считал, что лишь восстанавливает первичные истины и постигает сущности. Но с исторической дистанции более в чем 2500 лет он выглядит гениальным творцом-мыслителем, предвосхитившим и инициировавшим, наряду с другими такими же первопроходцами, «творческий взрыв» античной культуры, создавшей философию в попытке изменить духовный мир человека.

\section{СПИСОК АИТЕРАТУРЫ}

Адо, П. (2005) Ауховные упражнения и античная философия / пер. с франц. при участии В. А. Воробьева. М. ; СПб. : ИзА-во «Степной ветер» ; ИА «Коло». 448 с.

Белый, А. (1990) Революция и культура // Александр Блок, Андрей Белый: диалог поэтов о России и революции / сост., вступ. ст., коммент. М. Ф. Пьяных. М. : Высшая школа. 687 с. C. $471-489$.

Бердяев, Н. А. (1993) О назначении человека. М. : Республика. 383 с.

Горелов, А. А. (2013) Творчество, истина, смысл// Эпистемология креативности / отв. ред. Е. Н. Князева. М. : «Канон+» ; РООИ «Реабилитация». 520 с. С. 149-180.

Ааль, В. И. (1999) Толковый словарь живого великорусского языка : в 4 т. М. : Русский язык. T. $4.688 \mathrm{c}$.

Аиоген Ааэртский. (1986) О жизни, учениях и изречениях знаменитых философов / ред. и авт. вступ. ст. А. Ф. Аосев, пер. М. А. Гаспарова. М. : Мысль. 571 с.

Маслоу, А. (1997) Психология бытия / пер. О. О. Чистякова. М. : Рефл-бук ; Вакле. 304 с.

Платон (1993) Пир // Платон. Собрание сочинений : в 4 т. / общ. ред. А. Ф. Аосева, В. Ф. Асмуса, А. А. Тахо-Годи ; примеч. А. Ф. Аосева и А. А. Тахо-Годи. М. : Мысль. Т. 2.528 с. C. 81-134.

Порфирий (1986) Жизнь Пифагора // Аиоген Ааэртский. О жизни, учениях и изречениях знаменитых философов / ред. и авт. вступ. ст. А. Ф. Аосев, пер. М. А. Гаспарова. М. : Мысль. 571 с. Приложения. С. 416-426.

Тарновская, Е. О. (2003) Минувшее и непреходящее в жизни и творчестве В. С. Соловьева : материалы Междунар. конференции, 14-15 февраля 2003. СПб. : Серия «Simposium». Вып. 32. СПб. : Санкт-Петербургское филос. общество. 427 с. С. 384-388. 
Фрагменты ранних греческих философов (1989) / подг. А. В. Аебедев. М. : Наука. Ч. 1. От эпических теокосмогоний до возникновения атомистики. $576 \mathrm{c}$.

Франк, С. А. (1990) Непостижимое. Онтологическое введение в философию религии // Франк, С. $\Lambda$. Сочинения. М. : Правда. 608 с. С. 186-559.

Фуко, М. (2007) Герменевтика субъекта : Курс, прочитанный в Коллеж де Франс в 1981-1982 учебном году / пер. с фр. А. Г. Погоняйло. СПб. : Наука. 677 с.

Шюре, Э. (1990) Великие посвященные. Очерк эзотеризма религий / пер. с франц. Е. Писаревой. Репр. изд. Калуга: Типография Губернской Земской Управы. 419 с.

Runco, M. A. (1999) Self-Actualization // Encyclopedia of Creativity / ed. by V. F. Runco, S. R. Pritzker. N.-Y. : Academic Press. V. 2. 810 p. P. 533-536.

Аата поступления: 13.05.2019 2.

AWARENESS OF THE POSSIBILITY OF SELF-CREATION IN ANTIQUITY:

THE SCHOOL OF PYTHAGORAS

A. A. GoRELOV

RAS INSTITUTE OF PHILOSOPHY

T. A. GORELOVA

MOSCOW UNIVERSITY FOR THE HUMANITIES

The paper analyzes the meaning of the concept of «self-creation" and gives a distinction between the close concepts of "creativity", "self-improvement", "creativity of life", "culture of oneself" and "self-actualization". Self-creation is understood as a special kind of creativity relating to the creator themself, who tries to change themself in accordance with their ideas about the ideal. Creativity as a natural ability of the person has a moment of self-creation.

The first conscious attitudes of self-creation originate in the Axial Age in philosophy, and a systematic methodology for changing human behavior on its basis is found in the famous ancient school of Pythagoras. There, a special system of education was created, which makes it possible to reveal the potential of man and help them to achieve the moment of self-discovery. The Study of Pythagoras lays general foundations for the concept of self-creation.

Keywords: self-creation; creativity; self-improvement; creativity of life; self-culture; self-actualization; antiquity; Pythagoras

\section{REFERENCES}

Ado, P. (2005) Dukbovnye uprazbneniia $i$ antichnaia filosofiia/ transl. from Fr. Moscow, St. Petersburg, Stepnoi veter Publ., Publ. House Kolo. 448 p. (In Russ.).

Belyi, A. (1990) Revoliutsiia i kul'tura. In: Aleksandr Blok, Andrei Belyi: dialog poetov o Rossii i revoliutsii / comp. by M. F. P'ianykh. Moscow, Vysshaia shkola. 687 p. Pp. 471-489. (In Russ.).

Berdiaev, N. A. (1993) O naznachenii cheloveka. Moscow, Respublika. 383 p. (In Russ.).

Gorelov, A. A. (2013) Tvorchestvo, istina, smysl. In: Epistemologiia kreativnosti / ed. by E. N. Kniazeva. Moscow, Kanon+ ; ROOI Reabilitatsiia. 520 p. Pp. 149-180. (In Russ.).

Dal', V. I. (1999) Tolkovyi slovar' zhivogo russkogo iazyka : in 4 vol. Moscow, Russkii iazyk. Vol. 4.688 p. (In Russ.).

Diogen Laertskii. (1986) O zhizni, ucheniiakh i izrecheniiakh znamenitykh filosofov / ed. by A. F. Losev, transl. by M. L. Gasparova. Moscow, Mysl'. 571 p. (In Russ.).

Maslou, A. (1997) Psikhologiia bytiia / per. O. O. Chistiakova. Moscow, Refl-buk; Vakle. 304 p. (In Russ.).

Platon (1993) Pir. In: Platon. Sobranie sochinenii : v 4 t. / ed. by A. F. Losev, V. F. Asmus and A. A. Takho-Godi . Moscow, Mysl'. Vol. 2.528 p. Pp. 81-134. (In Russ.).

Porfirii (1986) Zhizn' Pifagora. In: Diogen Laertskii. O zbizni, ucheniiakb i izrecheniiakb znamenitykb filosofov/ ed. by A. F. Losev, transl. by M. L. Gasparov. Moscow, Mysl'. 571 p. Prilozheniia. Pp. 416-426. (In Russ.). 
Tarnovskaia, E. O. (2003) Vladimir Solov'ev i kontseptsiia «zhiznetvorchestva» A. Belogo. In: Seriia «Symposium». Minuvshee i neperekhodiashchee v zhizni i tvorchestve V. S. Solov'eva. Vol. 32 / Materialy Mezhd. konferentsii, 14-15 fevralia 2003. St. Petersburg, Sankt-Peterburgskoe filos. obshchestvo. 427 p. Pp. 384-388. (In Russ.).

Fragmenty rannikh grecheskikb filosofov (1989) / ed. by A. V. Lebedev. Moscow, Nauka. Vol. 1. Ot epicheskikh teokosmogonii do vozniknoveniia atomistiki. 576 p. (In Russ.).

Frank, S. L. (1990) Nepostizhimoe. Ontologicheskoe vvedenie v filosofiiu religii. In: Frank, S. L. Sochineniia. Moscow, Pravda. 608 p. Pp. 186-559. (In Russ.).

Fuko, M. (2007) Germenevtika sub »ekta: Kurs, procbitannyi v Kollezb de Fransv 1981-1982 uchebnom godu / transl. from Fr. by A. G. Pogoniailo. St. Petersburg, Nauka. 677 p. (In Russ.).

Shiure, E. (1990) Velikie posviasbchennye. Ocberk ezoterizma religii / transl. from Fr. by E. Pisarevoi. Repr. izd. Kaluga, Tipografiia Gubernskoi Zemskoi Upravy. 419 p. (In Russ.).

Runco, M. A. (1999) Self-Actualization. In: Encyclopedia of Creativity / Ed. by V. F. Runco and S. R. Pritzker. N.-Y., Academic Press. Vol. 2. 810 p. P. 533-536.

Submission date: 13.05 .2019$.

Горелов Анатолий Алексеевич - доктор философских наук, ведущий научный сотрудник сектора философских проблем творчества Института философии РАН. Адрес: 119842, Россия, г. Москва, ул. Гончарная, А. 12. Тел.: +7 (495) 697-91-28. Эл. адрес: evolepis@iph.ras.ru

Горелова Татьяна Анатольевна - доктор философских наук, профессор кафедры философии, культурологии и политологии Московского гуманитарного университета. Адрес: 111395, Россия, г. Москва, ул. Юности, д. 5. Тел.: +7 (499) 374-55-11. Эл. aдpec: fylosofy@mosgu.ru

Gorelov Anatoliy Alekseyevich, Doctor of Philosophy, Chief Research Fellow, Sector of Philosophical Issues of Creativity, RAS Institute of Philosophy. Postal address: 12, Goncharnaya St., Moscow, Russian Federation, 119842. Tel.: +7 (495) 697-91-28. E-mail: evolepis@iph.ras.ru

Gorelova Tatyana Anatolyevna, Doctor of Philosophy, Professor, Department of Philosophy, Cultural Studies and Political Science, Moscow University for the Humanities. Postal address: 5, Yunosti St., Moscow, Russian Federation, 111395. Tel.: +7 (499) 374-55-11. E-mail: fylosofy@mosgu.ru 